\title{
On Semantic Meaning of Manner in English Metaphorical Motion Events Based on Corpus
}

\author{
Shijie Wang \\ East China University of Science and Technology, Shanghai, China \\ Email: hazelwang321@qq.com
}

How to cite this paper: Wang, S.J. (2021) On Semantic Meaning of Manner in English Metaphorical Motion Events Based on Corpus. Open Access Library Journal, 8: e7781.

https://doi.org/10.4236/oalib.1107781

Received: July 22, 2021

Accepted: August 8, 2021

Published: August 11, 2021

Copyright $\odot 2021$ by author(s) and Open Access Library Inc.

This work is licensed under the Creative Commons Attribution International License (CC BY 4.0).

http://creativecommons.org/licenses/by/4.0/

\begin{abstract}
This paper researches the semantic meaning of manner in English metaphorical motion events (MMEs) qualitatively and quantitatively with the assistance of corpus. The discovery is made that the expressions of the semantic meaning of manner in mental states and emotional states exceed the other four target domains. In each target domain, manner verbs out numbers path verbs in types and quantities. The mechanism of manner verbs in English MMEs is expressed in V [manner], and V [manner] + Sat [path].
\end{abstract}

\section{Subject Areas}

Linguistics

\section{Keywords}

Metaphorical Motion Events

\section{Introduction}

An increasing number of scholars have devoted themselves to the research of motion events ever since the 1970s [1]. Metaphor, often considered as a way of thinking, is an important cognitive way for understanding and constructing the objective world [2]. Being one of the fundamental cognitive tools of human being, metaphor builds a channel for our understanding of abstract events or things by the tangible concept of motion, and thus constructs our own perception toward the world and ourselves. Previous research argues that the expression in physical motion (e.g., She crawled into the room) can extend to the way we process metaphorical motion (e.g., Suspicion crawled into my heart) [2].

Moreover, in the field of cognitive linguistics, the research of Motion Events has become a hot topic since the notion proposed by Talmy [3] [4], who defines 
a Motion Event as "a situation containing movement of an entity or maintenance of an entity at a stationary location". Metaphorical motion events thus concern cases where the predicted entities are not related to motion but use verbs that express movements (such as happiness surged through her) [2] [5].

The very existence of metaphorical motion events becomes indispensable in this sense. In comparison to actual physical motion events, however, the research on metaphorical motion events (MME) accounts for only a small part of motion event studies. Based on previous researches on motion events, and taking into consideration the importance of metaphor and motion on human cognition and language expressions, this paper intends to analyze and summarize the features of manner meaning in MME in English, and draw the conclusion on the semantic meaning of manner in English MME for future reference.

\section{Analysis on Semantic Meaning of Manner in MMEs}

\subsection{Methodology and Selection of Data}

In the corpus collection process, this paper borrows the ideas of Li Xue [6] and Deng Yu [1], and divides target domains of MMEs into six categories, which are mental states, emotional states, time, auditory perception, visual perception and other abstract conceptions. The above six categories are then chosen as target domains of MMEs in the research of corpus while the source domain is real spatial movement.

By searching online in Sketch Engine, the expressions of the MMEs below are retrieved from the English corpus of entire network by inputting different nouns common in the senses of facial features and mental state as keywords. In order to control unrelated variables and analyze data accurately, only three common nouns are input as keywords in searching verbs of each domain. Data are thus collected from the verbs that match different emotions and senses. In the process of collecting corpus from the search engine after inputting keywords, verbs are selected from the top 40 frequency of occurrence through manual identification. The verbs that belong to the MMEs are categorized and arranged in the following table in the order of their occurrence frequency as follows.

\subsection{Mental States}

1) a. My mind sometimes wanders during the course of the day, and I find myself thinking about why people find it so compellingly.

b. Numb with shock, I stood there, my mind reeling with confusion and panic.

c. I bet this thought has already crossed your mind, "Boy, investing this way is going to take a lot more work!”

d. A million thoughts were running rampant through her head and paralyzed her completely.

e. These were the thoughts swirling through my head tonight as I prepared to return to my relatively peaceful existence in Haris.

f. The idea grew as I became aware of the bond that my daughters share with 
females and all peoples of this world.

g. His words would shake my entire being; his astonishing and interesting ideas sparked a flame.

As shown in Table 1, mental states refer to the hypothetic process of feeling and thinking in philosophical and psychological sense. The mappings of MMEs can be divided into two types, namely moving entities and locations. In the examples above, the mental states conceptualized as spatial motions are mind, thought and idea. As is demonstrated in the examples, mind, thought and idea are conceptualized as moving entities that are able to move from one place to another in different directions. In Example 1c, thought is conceptualized as moving entities that moves into or out of the object of mind.

By categorizing verbs into manner verbs and path verbs, it can be readily discovered that manner verbs exceed path verbs considerably both in type and quantity. The semantic meanings of manner in MMEs are encoded in verbs, whereas the meanings of path are either omitted or encoded in particles such as prepositions and adverbs. In Example 1d, the semantic meaning of manner is encoded in the verb run to indicate the motion event of conceptualized moving entity thought, the path information in metaphorical motion of thoughts is encoded in the preposition through. According to examples above, the mechanism of semantic meanings of manner in MMEs can be concluded as $\mathrm{V}$ [manner], or $\mathrm{V}$ [manner] + Sat [path]. The template is used to format your paper and style the text. All margins, column widths, line spaces, and text fonts are prescribed; please do not alter them. You may note peculiarities. For example, the head margins in this template measures proportionately more than is customary. This measurement and others are deliberate, using specifications that anticipate your paper as one part of the entire journals, and not as an independent document. Please do not revise any of the current designations.

\subsection{Emotional States}

2) a. I cried that whole way home with happiness flooding my body.

b. I could just close my eyes for a second and happiness filled my heart instantaneously.

Table 1. Verbs of mental states.

\begin{tabular}{|c|c|}
\hline Mental states & Verbs \\
\hline $\operatorname{mind}(7)$ & wander, race, drift, reel, flash, spin, jump \\
\hline thought (6) & cross, enter, run, flash, swirl, flow \\
\hline idea (3) & strike, grow, spark \\
\hline path verbs (2) & cross, enter \\
\hline manner verbs (14) & $\begin{array}{l}\text { wander, race, drift, reel, flash, spin, jump, } \\
\text { run, flash, swirl, flow, strike, grow, spark }\end{array}$ \\
\hline total & 32 \\
\hline
\end{tabular}


c. I felt a great strength and happiness was overflowing within me to know that through my rough times the Emerge team has been there for me.

d. Fear heightened when the first patient was diagnosed in our country on September 30th.

e. Everything was removed at some point, all the equipment, but you can still feel this concentrated cold fear permeating the air.

f. Anger overwhelmed me; I didn't want anyone to know what had happened.

According to definitions in encyclopedia, emotion is subjective experience taking place in consciousness, and featured by psychological expressions, mental states and biological reactions. Li Xue [6] defines the mapping of emotional states as moving entities, in which emotions are conceptualized as spatial motions moving in or out of a certain object like body, heart or a certain person. The changing from one specific emotion to another is also conceptualized as motions with directions. Specific emotional states include happiness, anger, fear, love, shame and so on, as shown in Table 2. In Example 2a, the emotion happiness is conceptualized as a moving figure that goes through the body like flood. In some cases, the corresponding objects to which entities move may not exist. In Example 2d, the phrase fear heightened describes the metaphorical motion in which the emotion emerges and gradually intensifies, and the process of the motion is conceptualized as the direction of ascending.

Due to limitation in numbers of verbs collected, nearly all of the verbs above in the target domain of mental states are manner verbs with only three exceptions. In Example 2c, the verb overflow gives description to the metaphorical motions that the emotion of happiness expanding inside one's mind. In this case, the specific direction of the metaphorical motion in strengthening emotions is not specifically pointed out. It is worth clarifying that the preposition within signifies not the specific path of the emotion that is conceptualized as a moving object, but the location in which MME of emotion takes place. Except the path verb heighten in Example 2d, other verbs like flood, overflow, fill and overwhelm in the examples above belong to the category of manner verbs. It can be concluded that the mechanism of these manner verbs in English MMEs is V [manner].

Table 2. Verbs of emotional states.

\begin{tabular}{cc}
\hline Emotional states & Verbs \\
\hline happiness (6) & fill, overflow, flood, lie, radiate, flow \\
anger (6) & overwhelm, stir, flare, dissipate, cloud, mount \\
fear (7) & strike, permeate, creep, surround, dissipate, grip \\
path verbs (3) & heighten, permeate, surround \\
manner verbs (17) & $\begin{array}{c}\text { fill, overflow, flood, lie, radiate, flow, overwhelm, stir, flare, } \\
\text { dissipate, cloud, mount, strike, creep, dissipate, grip }\end{array}$ \\
total & 39 \\
\hline
\end{tabular}




\subsection{Time}

3) a. On the other hand, spring has arrived in Berlin and I have very little travel coming up.

b. Summer lingers in Paris and it's good for the Celine collection radiant.

c. Mr. Johnson evidently didn't how to relax, but as another summer is slipping away, you can.

d. A month went by in the blink of an eye, and then something happened that I thought wouldn't happen so fast.

e. I wonder how you would like to pass those fearful nights!

As is defined by encyclopedia, time is a non-spatial continuum in which events occur in apparently irreversible succession from the past through the present to the future. Being an abstract conception which is impossible to be seen or felt by human senses, time can be perceived only by means of being conceptualized into moving entities or locations. When being conceptualized as moving entities in spatial motions, time can be understood as moving towards a stationary observer or backwards from the observer, in which the positions of time and the observer is not absolute but relative. In Examples $3 \mathrm{a}, 3 \mathrm{~b}, 3 \mathrm{c}$ and $3 \mathrm{~d}$, the passing of time is conceptualized into spatial motions in which the observer is regarded as reference object, and the time moves further away from the observer. Under these circumstances, it can be inferred that the perspective of the observer is hidden in the contexts rather than directly pointed out its existence. In the metaphor TIME IS LOCATION, which is another mapping of time in MMEs, time is conceptualized as an immobile landmark that observers are moving towards, in or out of it. As is showed in Example 3e, the spending of time is conceptualized as spatial motions where the observers are passing through those fearful nights that are regarded as the location.

In comparison to mental states and emotional states, the verbs retrieved from search engine are outnumbered notably in types and quantities. And among the verbs in the target domain of time, path verbs and manner verbs share roughly the same amount as are shown in Table 3. In Example 3c, the manner verb slip indicates the speed that time passes by in the form of spatial motions. As the subject summer is conceptualized into moving figures, the information of path in the spatial motion of the time is encoded in the adverb away, signifying the enlarging distance between the time and the observer. Without the encoding of path information in particles is the manner verb linger, in which the semantic meaning of manner is solely represented. The mechanism of manner verbs in the examples above can be summarized into two types, being $\mathrm{V}$ [manner], and $\mathrm{V}$ [manner] + Sat [path].

\subsection{Auditory Perception}

4) a. Sounds travel easily from one class to the next, yet the thirst for a good education compels them to endure,

b. Nervous laughter floated up from the ground and Aefre looked down to see several women, 
Table 3. Verbs of time.

\begin{tabular}{cc}
\hline Time & Verbs \\
\hline spring (1) & arrive \\
summer (4) & linger, flow, slip, race \\
month (2) & pass, go \\
path verbs (3) & arrive, pass, go \\
manner verbs (4) & linger, flow, slip, race \\
total & 15 \\
\hline
\end{tabular}

c. But before he could fully grasp this fact, the computer's voice pierced the silence.

d. The sounds of classical Chelaxian music, conversation, and laughter drift out from the establishment and its subordinate taverns.

e. Where extended family gathered, hugs were shared, laughter bounced off the walls of the rooms.

Rather than being taken at its literal meaning, which is the contents or the meanings of the words, auditory perception should be defined as sounds or voices and their forms, and even lack of sounds such as silence. All of those mentioned above can be conceptualized into moving entities that move from one place to another in terms of spatial motions with apparent directions. In Example 4a, the sounds are conceptualized as moving entities that moves from one class to the next, in which a clear path is marked out clearly in the text. In Example $4 \mathrm{~b}, 4 \mathrm{~d}$ and $4 \mathrm{e}$, the starting location of the conceptualized spatial motions are expressed, such as float up from the ground, drift out from the establishment, and bounced off the walls, whereas the ending location of the metaphorical motions are vaguely indicated in the texts. In the Example 4c, both of the starting and ending location are omitted, leaving only the direction of the metaphorical motion of the voice.

In despite of the few data collected from corpus, it is evident that the number of manner verbs surpasses the one of path verbs as are shown in Table 4. In most of the examples above, the information of path in MMEs is represented in one or two particles following manner verbs. In Example 4e, the manner verb bounce gives vivid description of the wide spread and loudness of the laughter, while the path is incorporated in the adverb off. The mechanism of manner verbs in the examples above can be concluded as V [manner], and V [manner] + Sat [path].

\subsection{Visual Perception}

5) a. At last someone in the audience stirred and the warrior's glance darted away for but a split second while Anomen's stood still.

b. A glance shot back toward the altar and then men, before she goes through that last doorway. 
Table 4. Verbs of auditory perception.

\begin{tabular}{cc}
\hline Auditory perception & Verbs \\
sound (1) & travel \\
voice (2) & drip, pierce \\
laughter (3) & float, drift, bounce \\
path verbs (1) & travel \\
manner verbs (5) & drip, pierce, float, drift, bounce \\
total & 12 \\
\hline
\end{tabular}

c. In these, standing also in time to fall, shines the world's great tenderness, light and sight passingly touching like a kiss.

d. Lewis' vision swam as he pushed himself upright.

Visual perception is the capability to construe surrounding environments in processing information that is exposed in visible light. The type of mapping in the target domain of visual perception is SIGHT IS A MOVING ENTITY. The perception resulted from processing information in visible lights includes eyesight, glance, sight, vision and etc. In the Example 5a, glance is conceptualized as a moving figure that moves from one place to another in an explicit path. The examples $5 \mathrm{a}$ and $5 \mathrm{~b}$ give accurate description of the path in the conceptualized spatial motions, while Examples $5 \mathrm{c}$ and $5 \mathrm{~d}$ do not indicate the path of the conceptualized moving entities, but depict the MMEs with personified verbs touch and kiss.

Although searching results contain only a few data, the significant discrepancy occurs in Table 5 between the use of manner verbs (7) and path verbs (2). In the Examples $5 \mathrm{a}$ and $5 \mathrm{~b}$ where clear paths of conceptualized spatial motions are indicated, the information of path is encoded in one or two prepositions or adverbs following manner verbs. Meanwhile, the rest of the examples express the metaphorical motions of the conceptualized moving figures with only manner verbs in the means of personification, which are touch and swim. It can be concluded that the mechanisms of manner verbs in the examples are $\mathrm{V}$ [manner], and $\mathrm{V}$ [manner] + Sat [path].

\subsection{Other Abstract Conceptions}

6) a. The darkness creeps around us, swallowing the last breath of the fading world.

b. A curious change has come over the restaurant/café/pub industry in recent years which I have been watching with interest.

c. History sneaks its way in everywhere, and it is created every day in even the most humble of places.

d. where darkness flees when the light is brought in, or to where cold goes when the fire is lighted on our hearth. 
Table 5. Verbs of visual perception.

\begin{tabular}{cc}
\hline Visual perception & Verbs \\
\hline glance (7) & dart, wander, cast, shot, slide, cross, struck \\
vision (1) & swim \\
sight (1) & touch \\
path verbs (2) & cast, cross \\
manner verbs (7) & dart, wander, shot, slide, struck, swim, touch \\
total & 25 \\
\hline
\end{tabular}

Table 6. Verbs of other abstract conceptions.

\begin{tabular}{cc}
\hline Other abstract conceptions & Verbs \\
\hline darkness (3) & creep, flee, enter \\
change (1) & come \\
history (1) & sneak \\
path verbs (2) & enter, come \\
manner verbs (3) & creep, flee, sneak \\
total & 10
\end{tabular}

The analysis of manner verbs above belongs to those common target domains which are conceptualized as spatial motions in terms of MMEs. Additionally, a slight number of other abstract concepts exist in metaphorical motions conceptualized into spatial motions for better understanding. These concepts are comprised of a broad spectrum, ranging from history, change, darkness to influence, weather and etc. And mappings of MMEs include both types, i.e. moving entities and locations. The encoding and decoding of manner verbs as well as the representation of path information are similar to the examples in other five target domains.

From the analysis of the six target domains above, it can be evidently seen that in the mapping of entities, the three elements of a complete motion, i.e. the starting point, process of motion and the ending point in the conceptualized spatial motions, are represented flexibly in verbs and particles. In other words, elements above are possible to occur in one expression of one MMEs in the number of one to three, and in some cases, none. Similar flexibility in conceptualized spatial motions can be observed in the mapping of locations. The flexible representation of the conceptualized spatial motions is intertwined with the abundance of manner verbs as well as expressions of manner both in types and quantities.

Moreover, evidence from Table 6 above in different target domains shows that the verbs in mental states and emotional states surmount the other four target domains in types and quantities. Likewise, the path verbs are outnumbered by manner verbs considerably in each of the target domain in both types and quantities. 


\section{Conclusion}

This paper researches the semantic meaning of manner in English MMEs qualitatively and quantitatively with the assistance of corpus. After sorting out different expressions of MMEs in each target domain, the discovery is made that the expressions of the semantic meaning of manner in mental states and emotional states exceed the other target domains of MMEs, which are visual perception, time, auditory perception and other abstract concepts. In each of the target domain, manner verbs outnumber path verbs in types and quantities, the plethora of which are related to the flexible representation of the starting point, process of motion, and the ending point in conceptualized spatial motions. The mechanism of semantic meaning of manner in MMEs is expressed in ways of $\mathrm{V}$ [manner], and V [manner] + Sat [path].

\section{Limitation}

In the part of methodology, the identification and classification of the data are all finished manually by ourselves, which not only need to spend a lot of time and energy, but also may cause some faults due to the subjectivity of the author.

\section{Conflicts of Interest}

The author declares no conflicts of interest regarding the publication of this paper.

\section{References}

[1] Yu, D. (2019) A Corpus-Based Study of Manner Salience in Metaphorical Motion Events. Journal of Tianjin Foreign Studies University, Vol. 4, 102-112+161. (In Chinese)

[2] Lakoff, G. and Johnson, M. (1980) Metaphors We Live By. Chicago University Press, Chicago.

[3] Talmy, L. (1985) Lexicalization Patterns: Semantic Structure in Lexical Forms. Cambridge University Press, Cambridge.

[4] Talmy, L. (2000) Toward a Cognitive Semantics. Vol. 1 \& Vol. 2, The MIT Press, Cambridge, MA. https://doi.org/10.7551/mitpress/6847.001.0001

[5] Ozkaliskan, S. (2005) Metaphor Meets Typology: Ways of Moving Metaphorically in English and Turkish. Cognitive Linguistics, 16, 207-246. https://doi.org/10.1515/cogl.2005.16.1.207

[6] Xue, L. (2009) A Contrastive Study of Metaphorical Motion Expressions in English and Chinese. Foreign Language Research, Vol. 3, 44-47. (In Chinese) 